\title{
Educação Permanente em Saúde em um município da região metropolitana do Rio de Janeiro: saberes e práticas
}

\author{
Permanent health education in a city of the metropolitan region of Rio de Janeiro: knowledge and \\ practices
}

\section{Educación de Salud Permanente en una ciudad de la región metropolitana de Río de Janeiro: cono- cimiento y prácticas}

\section{Ana Paula Alves Gregório모 Endi Evelin Ferraz Kirby², Ivi Evelin Ferraz de Souza Jung ${ }^{3}$, Mônica Villela Gouvêa ${ }^{4}$}

Como citar esse artigo. Gregório, APA; Kirby, EEF; Jung, IEFS; Gouvêa, MV. Educação Permanente em Saúde em um município da região metropolitana do Rio de Janeiro: saberes e práticas. Revista Pró-UniverSUS. 2019 Jul./Dez.; 10 (2): 86-88.

\section{Resumo}

O objeto central da análise deste estudo é a Educação Permanente em Saúde (EPS) e sua constituição nas práticas locais de saúde. Objetiva investigar saberes e práticas sob a ótica da EPS em um município da região metropolitana do estado do Rio de Janeiro. Para tanto, será desenvolvida pesquisa do tipo descritiva e exploratória, com abordagem qualitativa. A coleta de dados acontecerá a partir de encontros conduzidos sob a perspectiva de Grupos Focais e entrevistas de aprofundamento. Os grupos focais com participação multiprofissional acontecerão em cinco encontros com cerca de 15 participantes incluindo trabalhadores da gestão e da assistência, de nível fundamental, médio e superior. As entrevistas serão conduzidas através de roteiro semiestruturado com informantes chave para aprofundamento das temáticas abordadas nos grupos focais. Serão incluídos no estudo trabalhadores da gestão e da assistência (atenção primária) que estejam atuando no município ao pelo menos 1 ano e concordarem em participar da pesquisa. Serão excluídos os trabalhadores que estiverem de férias ou de licença médica durante a fase de coleta de dados. Espera-se que o estudo possa fortalecer a EPS como norteadora de práticas e reflexões sobre o processo de trabalho e incentivar ações transformadoras nas realidades locais dos serviços de saúde.

Palavras-chave: Educação Continuada SUS, Educação Permanente.

\begin{abstract}
Objectives: The central object of the analysis of this study is the permanent education in health (EPS) and its constitution in the local health practices. The objective is to investigate knowledge and practices from the point of view of EPS in a municipality in the metropolitan region of the state of Rio de Janeiro. For this, a descriptive and exploratory research will be developed, with a qualitative approach. Data collection will take place from meetings conducted from the perspective of Focal Groups and deepening interviews. Focus groups with multiprofessional participation will take place in five meetings with about 15 participants including management, staff, primary, middle and senior level. The interviews will be conducted through a semistructured script with key informants to deepen the themes addressed in the focus groups. The study will include management and care workers (primary care) who have been working in the municipality for at least 1 year and agree to participate in the research. Workers on leave or medical leave during the data collection phase will be excluded. It is hoped that the study may strengthen the EPS as a guideline of practices and reflections on the work process and encourage transformative actions in the local realities of health services.
\end{abstract}

Keywords: Continuing Education SUS, Permanent Education

\section{Resumen}

Objetivos: El objeto central del análisis de este estudio es la Educación Permanente en Salud (EPS) y su constitución en las prácticas locales de salud. Su objetivo es investigar el conocimiento y las prácticas desde la perspectiva de EPS en una ciudad en la región metropolitana del estado de Río de Janeiro. Con este fin, se desarrollará una investigación descriptiva y exploratoria, con un enfoque cualitativo. La recopilación de datos se realizará a partir de reuniones realizadas desde la perspectiva de los grupos focales y entrevistas en profundidad. Los grupos focales con participación multiprofesional se llevarán a cabo en cinco reuniones con aproximadamente 15 participantes, incluidos los trabajadores de administración y atención, de nivel primario, medio y superior. Las entrevistas se realizarán a través de un guión semiestructurado con informantes clave para profundizar en los temas abordados en los grupos focales. Se incluirá en la gestión del estudio y los trabajadores de atención (atención primaria) que han estado trabajando en el municipio durante al menos 1 año y aceptan participar en la investigación. Se excluirá a los trabajadores de vacaciones o licencia por enfermedad durante la fase de recopilación de datos. Se espera que el estudio pueda fortalecer la EPS como guía para prácticas y reflexiones sobre el proceso de trabajo y fomentar acciones transformadoras en las realidades locales de los servicios de salud.

Palabras clave: Educación Continua SUS, Educación permanente,

Afiliação dos autores: 1. Enfermeira. Mestranda do programa de Mestrado Profissional em Ensino na Saúde/MPES, UFF, RJ, Brasil. Email: apag3@hotmail.com ORCID: https:// orcid.org/0000-0001-8054-542X

2. Enfermeira. Mestranda do programa de Mestrado Profissional em Ensino na Saúde/MPES, UFF, RJ, Brasil. Email: endiferraz@gmail.com ORCID: https://orcid.org/0000-0002$6250-3186$

3. Enfermeira. Mestranda do programa de Mestrado Profissional em Ensino na Saúde/MPES, UFF, RJ, Brasil. Email: ivi.jung@hotmail.com ORCID: https://orcid.org/0000-0002$7455-9363$

4. Doutorado em Odontologia. Professora do Programa de Mestrado Profissional em Ensino na Saúde/MPES, UFF, RJ, Brasil. Email: monicagouvea@gmail.com ORCID: https:// orcid.org/0000-0002-6552-8004 


\section{Introdução}

A Educação Permanente em Saúde (EPS) é a aprendizagem no trabalho baseada na possibilidade de transformar as práticas profissionais por meio de temas atualizados com novas propostas metodológicas, cientificas e tecnológicas. ${ }^{1}$

Para isso é preciso o encontro e a perspectiva da construção coletiva de saberes e práticas fundamentados no cotidiano do processo de trabalho. ${ }^{2}$ A EPS trabalha com ferramentas que buscam a reflexão crítica sobre a prática cotidiana dos serviços de saúde, sendo, por si só, um processo educativo aplicado ao trabalho que possibilita mudanças nas relações, nos processos, nos atos de saúde e nas pessoas.

A Educação Permanente é um processo que busca alternativas e soluções para os problemas reais de saúde vivenciados pelas pessoas e grupos em suas realidades. Ela representa mudança nas práticas dos trabalhadores. ${ }^{3}$ A partir dela o processo de trabalho em saúde torna-se coletivo; não mais prevalece o saber de forma hierárquica e vertical; ao contrário, utiliza-se o saber coletivo e a valorização do outro.

Nesse contexto, as tensões constituídas no processo de trabalho, apesar de exaustivas, são grandes oportunidades de produzir mudanças e compartilhamentos, sendo um instrumento necessário para análise do trabalho em ato. Através do resgate e a valorização do outro e sua história, podemos estimular a troca diária e explorar as tecnologias acessíveis, entendendo que trazendo um pouco disso para a cena, a problematização do processo de trabalho é que vai dar o direcionamento, prevalecendo a prática de ensinoaprendizagem a partir da realidade vivida, e fazendo das tensões constitutivas da rotina, grandes oportunidades de transformação.

As tensões, ainda que desconfortáveis, podem ser potentes instrumentos analisadores dos processos de trabalho instituídos, permitindo impulsionar a produção da novidade no trabalho da equipe. Entretanto, este novo só pode se dar se nos permitirmos deixar o nosso território de proteção, em que nos isolamos e protegemos, e buscarmos um encontro real com o outro, afetando e sendo afetado por este encontro. ${ }^{4}$

Aqui entra uma questão central, o fato de que enquanto os trabalhadores não construírem uma interação entre si, trocando conhecimentos e articulando um "campo de produção do cuidado" que é comum à maioria dos trabalhadores, não pode dizer que há trabalho em equipe. $\mathrm{O}$ aprisionamento de cada um em seu "núcleo específico" de saberes e práticas aprisiona o processo de trabalho as estruturas rígidas do conhecimento técnicoestruturado, tornando-o trabalho morto dependente. Ao contrário, o "campo de competência" ou "campo do cuidado", além da interação, abre a possibilidade de cada um usar todo seu potencial criativo e criador na relação com o usuário, para juntos realizarem a produção do cuidado. ${ }^{3}$

Neste sentido, um olhar mais profundo sobre a necessidade de formação e qualificação dos profissionais para o SUS é o objeto de meu interesse, sendo portanto esta a razão pela qual procurei a linha de Educação Permanente do Mestrado Profissional em Ensino na Saúde: Formação Docente Interdisciplinar para o SUS, onde espero problematizar e me qualificar para uma atuação mais fundamentada e assim, contribuir para o campo institucional e profissional da saúde coletiva.

Objetivo primário: Investigar saberes e práticas em EPS em um Município da Região metropolitana do RJ. Objetivos secundários: Analisar o contexto da gestão da EPS e das práticas de saúde em um município; Investigar os desafios da incorporação das ações de EPS no cotidiano do trabalho em saúde no município; Fortalecer a EPS como norteadora de práticas e reflexões sobre o processo de trabalho no município.

\section{Metodologia}

Trata-se de uma pesquisa descritiva e exploratória com abordagem qualitativa. Optou-se pela abordagem qualitativa, considerando o objetivo de estudar a Educação Permanente em um município da região metropolitana do estado do Rio de Janeiro.

A pesquisa qualitativa trabalha com o universo de significados, motivos, aspirações, crenças, valores e atitudes, o que corresponde a um espaço mais profundo das relações, dos processos e dos fenômenos que não podem ser reduzidos à operacionalização de variáveis. ${ }^{5}$

Assim, a pesquisa qualitativa preocupa-se com aspectos da realidade numa relação dinâmica entre o mundo real e o sujeito, isto é, um vínculo indissociável entre o objetivo e a subjetividade do sujeito que não pode ser traduzido em números, que não podem ser quantificados, centrando-se na compreensão e explicação das relações sociais. ${ }^{6}$

O estudo será realizado no município de Niterói no Programa Médico de Família onde a cobertura populacional total do PMF é de 327.750 pessoas, 7 o que representa cobertura de $64,04 \%$ da população do município de Niterói, utilizando como referência o total de 511.786 pessoas. $^{8}$

Este estudo utilizará um tipo básico de amostra não probabilística: a intencional, a partir da consulta a informantes-chave. São estabelecidos cinco tipos de informantes para estudos qualitativos: especialista, informante-chave, informante padrão, informante complementar e informante-extremista. A classificação, em cada caso, é dada pelo pesquisador a partir de critérios subjetivos relacionados ao objetivo da pesquisa. ${ }^{9}$

No estudo em questão, foi proposto o tipo 
informante-chave em que os sujeitos selecionados são considerados fontes de informação fundamentais por estarem profunda e diretamente envolvidos com os aspectos centrais da questão, o que faz com que não serem entrevistados, possa significar grande perda na qualidade dos dados da pesquisa.

Considerando o objeto da pesquisa, a seleção dos sujeitos participantes, envolverá um grupo multiprofissional composto por gestores e profissionais da assistência (nível fundamental, médio e superior), serão coletados os dados referentes a sexo, idade, formação, formação complementar (títulos, cursos), função e tempo de instituição.

A escolha dos informantes respeitará os seguintes critérios de inclusão: a) ser trabalhador da atenção primária do município de Niterói; b) ter no mínimo 01 ano de vínculo institucional; c) estar vinculado a condução de processos gerenciais/educacionais (coordenação, supervisão) ou assistenciais na instituição; e d) concordância com a participação na pesquisa.

Serão excluídos os trabalhadores que estiverem de férias ou de licença médica durante a fase de coleta de dados.

\section{Resultados Esperados}

O estudo poderá contribuir para pesquisa nas áreas de educação em saúde e para o adequado funcionamento do SUS, objetivando-se a qualidade de assistência à saúde ao usuário, assim como, o protagonismo e a emancipação do trabalhador. Espera-se, assim, fomentar o estímulo de novas pesquisas acerca do tema educação permanente em saúde e incentivar ações propositivas e transformadoras nas realidades locais em serviços de saúde municipais. Em última análise, acredita-se que o estudo guarda o potencial de contribuir com os diversos atores da saúde para a construção de cenários que propiciem a reflexão permanente das equipes de saúde sobre suas práticas, visando ampliar as capacidades institucional e profissional de atenção, de gestão, de participação social e de formação em sistemas locais de saúde.

\section{Referências}

1. Ceccim RB. Educação Permanente em Saúde: desafio ambicioso e necessário. Interface Comum Saúde Educ, Botucatu (SP) 2005; 9(16): 161-8Tavares CMM. Prática criativa da enfermagem psiquiátrica: fatores intervenientes no seu desenvolvimento. Esc. Anna Nery. 2002;6(1):107118.

2. Carrota F, Kawamura D, Salazar J. Educação permanente em saúde: uma estratégia de gestão para pensar, refletir e construir práticas educativas e processos de trabalhos. Saúde soc. Vol 18 supl.1 são Paulo Jan $\backslash$ mar,2009. Disponível em: https://www.scielo.br/pdf/sausoc/v18s1/08.pdf>

3. Franco T, Merhy EE. PSF: contradições e novos desafios. 1999.https:// eps.otics.org/material/entrada-outras-ofertas/artigos/PSF-contradicoes-enovos-desafios.
4. Mendonç PEX. (Luta)Em defesa da vida: tensão e conflito, reconhecimento e desrespeito nas práticas de gestão do Sistema Único de Saúde. 143 f. 2008. Dissertação (Mestrado em Medicina) -Faculdade de Medicina, Centro de Ciências da Saúde, Universidade Federal do Rio de Janeiro, 2008.

5. Minayo MCS. O desafio do conhecimento: Pesquisa Qualitativa em Saúde. (12 edição). São Paulo: Hucitec-Abrasco, 2010.

6. Minayo MCS. Análise qualitativa: teoria, passos e fidedignidade. Ciênc. saúde coletiva, v. 17, n. 3, p. 621-626, 2012 b.

7. e-Gestor AB disponível em: https://egestorab.saude.gov.br/.

8. IBGE - Instituto Brasileiro de Geografia e Estatística, 2019. Disponível: https://cidades.ibge.gov.br/brasil/rj/niteroi/panorama.

9. Quivy R, Campenhoudt LV. Manual de Investigação em Ciências Sociais, Lisboa, gradiva, 1992. 